Author Accepted Version. Final version published as: Temple, J. B., Rice, J. M., \& McDonald, P. F. (2017). Ageing and the economic life cycle: The National Transfer Accounts approach. Australasian Journal on Ageing, 36(4), 271-278.

\title{
Ageing and the Economic Lifecycle: The National Transfer Accounts Approach
}

\begin{abstract}
Objective: To illustrate the use of National Transfer Accounts (NTA) for understanding ageing and the economic lifecycle in Australia.

Methods: The NTA methodology is applied utilising a range of unit record, demographic and administrative data sets from 1981 to 2010.

Results: During early and later life, total consumption (public and private) is greater than labour income. On a time series and cohort basis we show that each successive generation has improved their level of well-being (as measured by consumption) relative to the previous years or previous cohorts from 1981-82 onwards. We also show a substantial increase in labour income earned by mature age workers over this period. International comparisons show Australia to have consumption and labour income age profiles very similar to those of Canada but dissimilar to many other countries, driven by differences in demographic and policy settings.

Conclusion: The NTA approach provides a powerful framework to track differences in the economic lifecycle across age groups, across time, across cohorts and across countries.
\end{abstract}

Keywords: Ageing, Economic Models, Population Dynamics 


\section{Impact Statement}

The National Transfer Accounts framework outlined herein offers a comprehensive approach to inform policy debates on how changes in population age structure affect economic growth, the well-being of all age groups, and the sustainability of public and private systems that transfer resources, across time, across generations and across countries. 


\section{Ageing and the Economic Lifecycle:}

\section{The National Transfer Accounts Approach}

\section{Introduction}

The economic role of mature age Australians as producers of goods and services and consumers of public resources in particular has become a key issue in policy discussions. The regular Intergenerational Reports are the Government's primary tool to track the demographic and economic issues associated with the continued ageing of Australia's population [1-4]. Despite their contribution to public debate, these studies are oftentimes subject to criticism due to scope, changing assumptions and recently, politicisation of the document [5-7].

More generally, studies on the economics of ageing are criticised for their failure to examine the full transfer system that governments, families and individuals engage in to fund consumption across the lifecycle. With increased longevity and limited upward movement in the age at retirement, most high income countries have developed an extended period at the end of the lifecycle with reduced labour market attachment. In addition, extensions of time in education have tended to delay full-time labour market participation at younger ages. Despite these trends, many studies gloss over the transfer systems that serve to fund consumption in the earlier and later stages of the life course. A further limitation of many economic studies on population ageing is their failure to generalise findings about the impact of ageing on the economy beyond the specific confines of their study - comparing countries at different times in demographic and economic development, with differing cultural, political and social systems. 
The National Transfer Accounts (NTA) project seeks to bridge this gap through the development of a unified (cross-country and across time) theoretical and methodological framework for the analysis of intergenerational economic issues. The NTA is colloquially referred to as 'adding age to the national accounts', as central to the approach is the disaggregation of national level aggregate statistics on economic phenomena by age. By doing so, the NTA seeks to improve our understanding of what we term the generational economy: "the social institutions and economic mechanisms used by generations or age groups to produce, consume, share and save resources" [8; p.1]. This type of analysis contributes to an understanding of how changes in population age structure are affecting economic growth, the well-being of all age groups, and the sustainability of public and private systems that transfer resources between generations.

In this paper, we outline the NTA approach to examining the intersection of ageing and economic roles throughout the life course, through an analysis of one account component: the economic lifecycle of production and consumption. Following a discussion of the NTA conceptual framework and methodology, we present results showing the utility of the NTA approach in examining the economic lifecycle (i.) at a point in time, (ii.) across age groups and cohorts over time, and (iii.) across countries. We conclude with an examination of limitations and extensions to the NTA project currently underway to further improve its scope. 


\section{Methods}

One purpose of the Australian NTA project is to document the economic life cycle through the NTA system: that is, the age-related patterns of consumption and labour income that are associated with the life cycle of education, work, and retirement. Specifically, the NTA is "a system of macroeconomic accounts that measures current economic flows by age in a manner consistent with the United Nations System of National Accounts. NTA measures age-specific labour income, asset income, consumption, transfers and saving, accounting for flows within households, between households, through the public sector and with the rest of the world" [9; p. 199].

The Australian NTA project forms part of a large international project with research teams producing accounts for over 80 countries in the Asia-Pacific, Americas, Europe and Africa, covering a population of over 6 billion people. The NTA project began in 2004 led from the East-West Center (University of Hawaii) and the Center for the Economics and Demography of Aging, University of California at Berkeley. A detailed overview of the theoretical and mathematical basis of the NTA system, as well as detailed descriptions of methodology, country case studies and cross-country comparisons are available elsewhere [9-12].

Fundamental to the NTA approach is the detailed construction of accounts that map the economic lifecycle - the patterns of production and consumption that vary by age, generating periods in life in which one exceeds the other. Where these shortfalls exist, mostly in childhood and later life, public and private transfers or reallocations are required to meet the gaps. These transfers can be from the public sector (eg. the Age 
Pension, subsidised pharmaceuticals etc), inter or intra household transfers (eg. parents paying for children's education) or drawing upon income from previously accumulated assets or upon savings (eg. drawing upon superannuation or dissaving).

The NTA includes a number of sub-accounts, and in this paper, we focus on the headline results from the Economic Lifecycle account, which details labour income and consumption (Table 1). For example, the economic lifecycle account includes measures of the private and public consumption of education, health and housing by different age groups. These account items are consistent across all countries in the international NTA project. Other accounts include the public age reallocation account and private age reallocation account, which measure how consumption is funded when consumption exceeds labour income (Table 1). New accounts for assets and liabilities have also been produced for Australia [13]. As will be discussed later in this paper, new accounts for time transfers in the household sector are now part of the NTA methodology.

\section{$<$ TABLE 1 - ABOUT HERE $>$}

The NTA methodology has been developed to maximize comparability between different countries, and across time. This has led to a flexible modelling approach where numerous data sources and methods are employed to estimate the underlying account items. The procedures are extremely detailed and the interested reader is directed to the United Nations manual [9]. However, the general approach is to firstly, calculate the aggregate benchmarks for the total economy (of consumption, labour income, public age reallocations and private age reallocations) derived from National Accounts or equivalent data sources. Secondly, using a combination of sample survey and 
administrative data, an age profile is fitted to the benchmark. When individual level data are not available (i.e, data are only available at the household level), allocations must be made from the household to individual members to generate the age profile. The NTA methodology uses a number of strategies including regression, iterative fitting, equivalence scales and an equal benefit approach, depending on the item under analysis [9].

In addition to ABS demographic data, this project draws heavily upon ABS sample surveys including the Household Expenditure Survey, Survey of Income and Housing, and Survey of Disability, Ageing, and Carers, as well as the Australian System of National Accounts and administrative data on programmatic expenditure. The sample survey data were predominately used to fit age profiles to each of the account items in table 1, whereas data from National Accounts and administrative data are used to estimate aggregate benchmarks.

\section{Results}

\section{Cross-sectional results}

Figure 1 displays the key concepts from the economic lifecycle account, including consumption, labour income and the life cycle deficit for the financial year, 2009-10. Consumption refers to the total goods and services that satisfy the needs and wants of residents and comprises both public and private consumption on items such as housing, education and health (Table 1). In the NTA framework, labour income is comprised of labour earnings inclusive of fringe benefits, and self-employed labour income. The 
difference between total consumption and labour income, is termed the life cycle deficit.

NTA data can be presented on both a per-capita and aggregate basis. Per capita profiles show the average levels of production and consumption per age category, whereas the aggregate profiles express the total economy-wide values produced, consumed or transferred for each age category. In 2009-10, younger Australians consumed while earning negligible amounts of labour income (Figure 1). A similar situation is found among older Australians who have significant levels of consumption while earning lower amounts of labour income. In contrast, Australians of prime working age earned more in labour income than they consumed. This relationship is summarised in the average per capita age profile for the life cycle deficit which is simply the difference between consumption and labour income. This general relationship is observed across all countries in the NTA network although, as will be shown, the national age profiles differ considerably.

\section{Time Series results}

An important limitation of the results presented above is they show age profiles at only one point in time. How have these age patterns of labour income and consumption differed over time in Australia, particularly in the last 30 years, a period of considerable demographic and economic change [14]? Results in Figure 2 show the per capita levels of labour income and consumption from 1981-82 through to 2009-10, standardised to 2009-10 Australian (AUD) dollars. Over time, consumption rises across all age groups. That is, for each particular age group, later generations appears to have higher living standards than earlier generations, on average. While the benefits of economic growth 
may not have been spread equally within age groups, when looking across age groups it is evident that total consumption (an important measure of well-being) has increased considerably for all age groups.

These data also show significant shifts across time in the economic production of older Australians as measured by their labour income. This is shown by the outward shift of the labour curve over time, which was particularly pronounced during the 2003-04 to 2009-10 period. This later period coincides with a significant increase in mature age labour force participation [15]. Moreover, across time, there has been a significant increase in average labour income earned by persons in the primary working ages, much of which has been driven by the increasing labour force participation of women [14]. However, for young Australians (under age 25), the shifts in average earnings over time have been small primarily because of increasing participation in education, although their consumption has increased through increases in public and private transfers to them.

\section{Cohort results}

Using the multiple cross-sections of NTA data, it is possible to construct cohort trends across each variable. That is, it is possible to view trajectories of people born in the same years across time as they age. Figure 3 compares the 2009-10 cross-sectional profile of per capita labour income with the birth cohort profiles. Each solid line represents the labour income of a cohort as the cohort has aged from 27 through to 55, 37 through to 65 and so on. 
An important finding from this graph is that peak income has been achieved at a later age for cohorts than is the case for the cross-sections. This is because incomes have risen cross-sectionally at all ages across time. However, for the later birth cohorts (028 and 7-35), the age at peak income seems to be matching the early cross-sectional peak income. In contrast, average incomes at older ages have continued to rise strongly across cohorts. It is clear from these cohort comparisons that more recent cohorts of older Australians have fared better in the labour market when compared to their predecessors. These results also underscore the fact that different cohorts experience the economic life cycle in different ways, indicative of different levels of education, macro-economic and social conditions as they enter, progress through and leave the labour market.

\section{International Comparisons}

One key benefit of the NTA approach is the utilisation of a standardised methodology to compare populations at differing points of the demographic transition, with different levels of population ageing under different cultural, political and policy settings. Herein we present comparisons of Australia's labour income and consumption with China, Japan, United States, Canada and Sweden. The first three countries are Australia's top three trading partners [16]. Canada is included as it has a very similar public transfer system and a similar economy to Australia. Sweden is included as an outlier, with very generous public transfers and high taxes relative to other countries. The figures below are normalised across countries relative to the average values for persons aged 30 to 49 (shown as a ratio of 1 ). 
Viewing Figure 4, there are a number of similarities and differences in the consumption and labour income age profiles across countries. Given similar economies, welfare systems and migration policies, it is not surprising that the age profiles of consumption are very similar between Canada and Australia. Indicative of low and middle income countries in the NTA network, consumption is higher in the early life course but lower in the later life course in China. As expected, given generous welfare and care provisions in Sweden, consumption is high in both early and later life. Japan has a similar later life consumption profile as the US, but consumption is relatively high among younger ages in Japan also. Recalling that the comparison age group is 30-49, it is not surprising that the United States has relatively high consumption in later life. Low levels of public transfers are available to those of working age in the United States, which constrains consumption during these ages. Consumption in later life in the United States is also higher due to the significantly higher levels of labour income in the later life course when compared to other countries[11]. This is evident by the labour income curve for the United States, which is skewed to the right relative to the other countries (Figure 4).

Again, Canada has the labour income profile most similar to Australia. However, like China (but to a much lesser extent), labour income tends to rise more quickly in Australia at younger ages. A stark comparison is Japan, where the labour income profile does not peak until the early 50s at a value 20 per cent higher than the average for those aged 30 to 49 , dropping very quickly from the mid to late 50 s. This is indicative of the seniority system and retirement age in Japan acting in tandem, in which salaries rise with age but the onset of retirement is very rapid and society-wide. A strong drop in 
labour income is also evident in Sweden, though more gradual than the severe case in Japan.

\section{Discussion}

Focusing on the economic lifecycle account of the NTA, this paper has sought to show the multiple dimensions in which ageing, production and consumption can be considered: cross-sectionally, as a time-series, as a cohort and in a cross-country setting. This enables the economic lifecycle of ageing to be considered from multiple perspectives, each providing complementary but alternative views. The results presented in this paper underscore the fact that different cohorts experience ageing and the economic life cycle in different ways, indicative of different levels of education, macro-economic and social conditions as they enter, progress through and leave the labour market.

Notwithstanding, consumption is greater than labour income in the later life course irrespective of whether ageing and the economic lifecycle is considered crosssectionally, on a time series and a cohort basis, or across countries. This expected finding is not necessarily a problem for the macro-economy. What is important is the age reallocations that exist to fund the lifecycle deficit, and the sustainability of these transfer systems over time. Indeed, results presented here show a significant increase in average labour income earned by mature age Australians over the last 30 years, but particularly in more recent times. In subsequent papers, we are examining the funding mechanisms whereby transfers fund the gap between consumption and labour income for older Australians. This is particularly important as much of the concern commonly 
expressed about population ageing relates to age specific public sectors programs (eg., Age Pension, PBS). However, this needs to be placed in the context of a range of government programs funded by government, the role of private consumption in substituting for public programs and the extent to which reallocations, whether between households or from asset-based sources, fund continued consumption.

As noted by Kendig and Woods, it is important to disaggregate the costs attributable to population ageing from other factors such as technological or sectorial changes [6]. This is underscored by the results of the international comparisons which show the importance of policy settings and cultural and demographic factors in the shape and height of consumption and labour income curves in the later life course. This is even more pronounced in international comparisons of intergenerational transfer systems and projected lifecycle deficits, as the world population continues to age [11]. The ability to disaggregate the potential impacts of population ageing on economies and families across countries is a key advantage of the NTA approach.

Despite these strengths, there are two key limitations to the National Transfer Accounts approach, which recent methodological advances are helping to overcome. The first limitation is that the Australian NTA is constructed to be broadly consistent with and complementary to the Australian System of National Accounts and, as such, shares in its limitations. One limitation is that services provided by the household sector for the household sector are excluded. The exclusion of these services is an issue for the Australian NTA, in particular, because who produces and who consumes these services can be expected to vary greatly by age and by sex, particularly for unpaid caring work. Indeed, research consistently shows that older Australians engage in nonmarket 
activities that shadow market provided services such as unpaid care and volunteering [17-18]. A new advance made to the NTA methodology is the inclusion of non-market activities into the NTA. Results have recently been published for a number of European countries [19-20]. These NTA studies underscore an asymmetry in private intergenerational transfers, whereby "men are net donors of money to other age groups during their working life, women are net donors of time to other household members" [20; p.689]. Unfortunately, these advances in methodology come at a time when funding for the ABS Time Use Survey has been cut in Australia. Previously, Time Use Surveys have been conducted by the ABS in 1992, 1997 and 2006. However, the ABS abandoned plans for a 2013 survey due to funding cuts. We are currently investigating pathways to incorporating this important area of research.

This point highlights the second limitation of the standard NTA approach, which is that it does not consider inequalities or differences within specific age groups. The methodology, as it stands, disaggregates flows by age. However, there are significant differences in the ways in which production, consumption and intergenerational transfers differ within rather than between age groups. Again, methodological advances have started in this area with countries constructing NTA data from the perspective of gender and socio-economic status [21-22]. Nonetheless, there remains a need for further research on within age group inequalities in the later life course.

A further extension to the NTA framework is the use of simulations and projections to understand the policy implications of population ageing. For example, the UN has recently released projections of detailed dependency and support ratios across the world using the NTA framework [23]. Others have examined projections of individual account items (such as health care), or built overlapping generation models using NTA 
data [24-25]. A research priority of the Australian NTA team is to build a simulation model from NTA data to examine the interaction between Australia's shifting demography and the efficacy of extant formal and informal intergenerational transfer systems.

Noting these limitations and extensions, the NTA provides a comprehensive framework to examine the production, consumption and transfer behaviours that reflect the generational economy. Taken together with recent methodological advances in the NTA project, this will enable a more comprehensive view of the economic role of older persons that has heretofore been omitted from much economic analysis of population ageing.

\section{References}

1. Australian Treasury. 2002 Intergenerational Report 2002-03. Canberra: Australian Government, 2002.

2. Australian Treasury. 2007 Intergenerational Report. Canberra: Australian Government, 2007.

3. Australian Treasury. 2010 Intergenerational Report, Australia to 2050: Future Challenges. Canberra: Australian Government, 2007.

4. Australian Treasury. 2015 Intergenerational Report, Australia in 2055. Canberra: Australian Government, 2015. 
5. Kendig, H. 2010. The Intergenerational Report 2010: A double-edged sword. Australasian Journal on Ageing 29(4): 145-146.

6. Kendig, H and Woods, M. 2015. Intergenerational Report 2015: A limited and political view of our future. Australasian Journal on Ageing 34(4): 217-219.

7. Fine, M. 2014. Intergenerational perspectives on ageing, economics and globalisation. Australasian Journal on Ageing 33(4): 220-225.

8. Patxot, $\mathrm{C}$ Lee, $\mathrm{R}$ ad Mason, A. 2015. Special Issue on Exploring the Generational Economy. The Journal of the Economics of Ageing. 5: 1-6.

9. United Nations (UN). 2013. National Transfer Accounts Manual: Measuring and Analysing the Generational Economy. United Nations: New York.

10. Lee, R., Mason, A. 2011. Generational Economics in a Changing World. Population and Development Review 37(S1): 115-142

11. Lee, R., Mason, A. 2011. Population Aging and the Generational Economy: A Global Perspective. Edward Elgar, Cheltenham, UK.

12. National Transfer Accounts. 2017. National Transfer Accounts Website. http://www.ntaccounts.org/web/nta/show/ 
13. Temple, J McDonald, P and Rice, J. 2017. Net Assets Available at Age of Death in Australia: An Extension of the National Transfer Accounts Methodology. Population Review (forthcoming).

14. Temple, J and McDonald, P. 2008. Is Demography Destiny? The Role of Structural and Demographic Factors in Australia's Past and Future Labour Supply. Journal of Population Research 25(1): 29-49.

15. Temple, J Rice, J and McDonald, P. 2017. Mature Age Labour Force Participation and the Life Cycle Deficit in Australia: 1981-82 to 2009-10. Journal on the Economics of Ageing (forthcoming)

16. DFAT. 2017. Australia's Trade at a Glance: Web Tool. Available from: http://dfat.gov.au/trade/resources/trade-at-a-glance/Pages/default.aspx. $\quad$ Date accessed: May 2017, Department of Foreign Affairs and Trade: Canberra.

17. Brandon, $\mathrm{P}$ and Temple, J. 2006. Determinants of Time Allocation Combinations among Non-Employed Older Persons: Evidence from Australian Time Use Diaries. Australian Journal of Social Issues. 41(1).

18. Ransijn, R Hartford, J and Andrews, G. 2002. Ageing and the Economy: costs and benefits. Australasian Journal on Ageing 21(3): 145-. 
19. Vargha, L., Gal, R., Crosby-Nagy, M. 2017. Household production and consumption over the life cycle: National Time Transfer Accounts in 14 European countries. Demographic Research 36: 605-944.

20. Renteria, E Scandurra, R Souto, G and Patxot, C. 2016. Intergenerational money and time transfers by gender in Spain: Who are the actual dependants? Demographic Research 34(24): 689 - 704.

21. Jimenez-Fontana, P. Analysis of non-remunerated production in Costa Rica. The Journal of the Economics of Ageing. 5: 45-53.

22. Mejia-Guevara, I. Economic inequality and intergenerational transfers: Evidence from Mexico. The Journal of the Economics of Ageing. 5: 23-32.

23. Mason, A. Lee, R. Abrigo, M Lee, S. 2017. Support ratios and demographic dividends: Estimates for the world. New York, Population Division, United Nations.

24. Mason, C Miller, T. 2017 International projections of age-specific healthcare consumption: 2015-2050. The Journal of the Economics of Ageing.

25. Patrick, G Seckin, A. From pro-natalist rhetoric to population policies in Turkey? An OLG general equilibrium analysis. Economic Modelling. 93. 


\section{University Library}

\section{- M M N E R VA A gateway to Melbourne's research publications}

Minerva Access is the Institutional Repository of The University of Melbourne

Author/s:

Temple, JB;Rice, JM;McDonald, PF

Title:

Ageing and the economic life cycle: The National Transfer Accounts approach

Date:

2017-12-01

Citation:

Temple, J. B., Rice, J. M. \& McDonald, P. F. (2017). Ageing and the economic life cycle:

The National Transfer Accounts approach. AUSTRALASIAN JOURNAL ON AGEING, 36 (4), pp.271-278. https://doi.org/10.1111/ajag.12486.

Persistent Link:

http://hdl.handle.net/11343/253834 